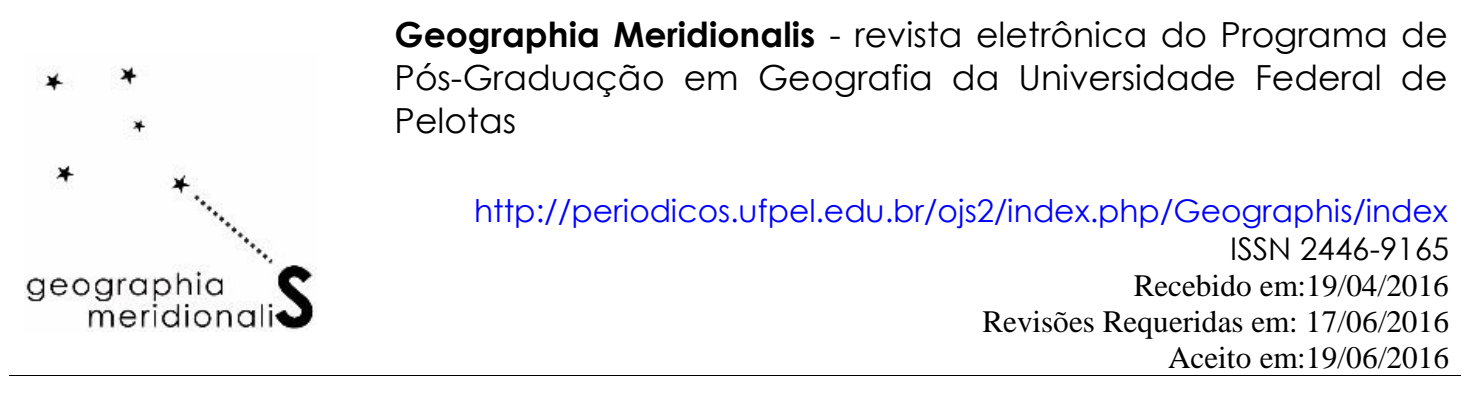

\title{
O IMPACTO AMBIENTAL SOBRE AS POPULAÇÕES DE AUSTROLEBIAS (PISCES: CYPRINODONTIFORMES: RIVULIDAE) COM A CONSTRUÇÃO DE UM DIQUE DE CONTENÇÃO NO BANHADO DO PONTAL DA BARRA, PELOTAS, RS
}

\begin{abstract}
Morevy Moreira Cheffe Grupo Especial de Estudo e Proteção do Ambiente Aquático do Rio Grande do Sul Setor de Ictiologia, Divisão de Fauna mcheffe@hotmail.com

Giovanni Nachtigall Maurício Grupo Especial de Estudo e Proteção do Ambiente Aquático do Rio Grande do Sul Setor de Ictiologia, Divisão de Fauna Universidade Federal de Pelotas Curso Superior de Tecnologia em Gestão Ambiental gnachtigallmauricio@yahoo.com.br

Ândrea Lenise de Oliveira Lopes Universidade Federal de Pelotas Mestranda do Programa de Pós-Graduação em Geografia lopes.andrea.geo@gmail.com
\end{abstract}

\section{1 - Introdução}

Em decorrência da cheia da laguna dos Patos e do canal São Gonçalo, ocorrida em outubro de 2015, o Poder Público Municipal de Pelotas efetuou a construção de um dique de contenção em meio ao banhado do Pontal da Barra, na praia do Laranjal. Tal dique teria como propósito impedir o avanço das águas, que ocorria a partir do canal São Gonçalo e da laguna dos Patos, sobre zonas residenciais no balneário Valverde. O dique foi construído sobre uma rua pré-existente, que corta o banhado do Pontal da Barra em duas metades, uma para sul e outra para norte da via. Os aspectos técnicos que envolvem a construção e operação do dique foram alvo de uma nota técnica, publicada em dezembro de 2015 (Silva et al., 2015). De acordo com essa nota, "por ser uma área de banhado, onde há uma grande biodiversidade, é necessário que seja realizado um estudo sobre espécies que possam ser afetadas pela criação dessa barreira e tenham seu fluxo gênico 
seccionado" (Silva et al., 2015: 5). Assim, a presente nota técnica segue a sugestão de Silva et al. (2015), trazendo uma avaliação dos impactos criados pela construção dessa barreira sobre duas espécies de peixes anuais, a saber, Austrolebias nigrofasciatus Costa \& Cheffe e Austrolebias wolterstorffi (Ahl), ambos oficialmente considerados ameaçados de extinção em nível nacional (Portaria no 445/2014 do Ministério do Meio Ambiente) (BRASIL, 2014) e estadual (Decreto Estadual n ${ }^{\circ}$ 51.797, de 08 de setembro de 2014) (RIO GRANDE DO SUL, 2014).

Ainda segundo Silva et al. (2015), o Pontal da Barra se caracteriza por ser um ponto extremamente crítico em relação à circulação de água e sedimentos, observação que permite inferir que o sistema hidrológico local será negativamente impactado pela presença do dique, o qual atuará como barreira à livre circulação das águas e ao fluxo natural de sua fauna e flora associadas.

Os peixes anuais são biologicamente adaptados a ambientes aquáticos temporários, que parte do ano estão secos e parte com lâmina d'água. Possuem ciclo de vida curto, atingindo a maturidade sexual em algumas semanas, e morrendo quando os corpos d'água que são seu habitat secam (Lima, 2008). Seus ovos, durante o período seco, mantêm-se no estado de diapausa e eclodem após os charcos recuperarem sua lâmina de água (Lima, 2008). Em outras palavras, o ciclo de vida dos peixes anuais é totalmente influenciado pelos hidroperíodos.

\section{2 - Desenvolvimento}

Para melhor compreensão dos hidroperíodos aos quais o banhado do Pontal da Barra está sujeito adotou-se a divisão estacional das regiões de clima temperado (Odum, 1959), que admite seis estações: Outonal, Hibernal, Pré-vernal (princípio da Primavera), Vernal (final da Primavera), Estival (princípio do Verão) e Serotinal (final do Verão).

Os ciclos de eclosão (reproductive bloom), assim como a diapausa embrionária no período estival, fazem parte da estratégia biológico-reprodutiva dos peixes anuais do grupo Austrolebias adloffi e são responsáveis pela perpetuação desses rivulídeos. Os ciclos de eclosão possivelmente surgiram como uma resposta estratégica para as variações sazonais dos níveis pluviais, sujeitos a influências drásticas determinadas por fenômenos meteorológicos como El Niño e La Niña. A estratégia de ciclos (bloons) garante um 
plantel mínimo de reprodutores em hidroperíodos atípicos, como o início do Serotinal ou final do Vernal. Esse fato pode determinar a ocorrência de duas, ou mais raramente três, classes de tamanho em desenvolvimento gonadal distinto, em um mesmo biótopo isolado (e.g. charco temporário, banhado pluvial). Os ciclos de eclosão de Austrolebias nigrofasciatus (Tabela 1), conforme dados coletados no Pontal da Barra entre Março de 1999 e Abril de 2000, são quatro, assim denominados: Precoce, Pioneiro, Colonizador e Tardio. No ciclo Precoce as pós-larvas eclodem no final do período Estival ou início do Serotinal, conforme a precipitação e o encharcamento das águas meteóricas. Os exemplares crescem e atingem a maturidade sexual no período Outonal. O ciclo Pioneiro eclode no final do Serotinal ou início do Outonal e os exemplares atingem a maturidade no período Hibernal. Este é o ciclo clássico, o mais comum, sendo observado em quase todos os biótopos - incluindo os que possuem apenas um único bloom reprodutivo. $\mathrm{O}$ ciclo Colonizador verifica-se no final do Outonal ou início do Hibernal - justamente no período usual de maior precipitação pluviométrica - e atinge a maturidade sexual no PréVernal. É denominado “colonizador" por ser o ciclo que pode abrigar mais de uma classe de tamanho e maturação (juvenis recém eclodidos e adultos maturos do ciclo anterior) e por mecanicamente dispersar esses exemplares através da conexão dos biótopos aquáticos, antes isolados. Esse é o ciclo fundamental, pois além de propiciar a colonização de novos ambientes, possibilita a troca de genes entre as diversas sub-populações garantindo assim a plasticidade e a viabilidade genética. No ciclo Tardio, que começa no final do Hibernal ou início do Pré-Vernal, os exemplares atingem a maturidade sexual no final do Pré-Vernal ou início do Vernal - período de menor precipitação de águas meteóricas. Apenas ambientes amplos, com grande variedade de áreas úmidas (e.g. banhados, charcos, turfeiras, paleodrenos), possuem três ou quatro ciclos de eclosão. Áreas menores e com pouca diversificação de biótopos aquáticos, ou ambientes isolados e sem conexão em nenhum período, não conseguem abrigar populações multicíclicas. Esse fenômeno estratégico ainda não foi verificado em espécies de Austrolebias pertencentes aos clados dos subgêneros Acantholebias, Acrolebias, Argolebias, Cypholebias, Gymnolebias e Megalebias. 
Tabela 1 - Extensão dos ciclos de eclosão (bloons) do peixe anual Austrolebias nigrofasciatus nos períodos estacionais, da eclosão (*) a reprodução e morte (+).

\begin{tabular}{|c|c|c|c|c|c|c|}
\hline \multirow[t]{2}{*}{ BLOONS } & \multicolumn{5}{|c|}{ ESTAÇÕES } & \multirow[b]{2}{*}{ Vernal } \\
\hline & Estival & Serotinal & Outonal & Hibernal & $\begin{array}{l}\text { Pré- } \\
\text { Vernal }\end{array}$ & \\
\hline Precoce & *--- & $\begin{array}{c}-\cdot-\cdot---- \\
-\end{array}$ & ---+ & & & \\
\hline Pioneiro & & *--- & ------------ & ---+ & & \\
\hline Colonizador & & & *--- & ---------- & ---+ & \\
\hline Tardio & & & & *.-- & -------- & ---+ \\
\hline
\end{tabular}

Fonte: Os autores

Figura 1 - Mapa de distribuição geográfica de peixes anuais no Pontal da Barra

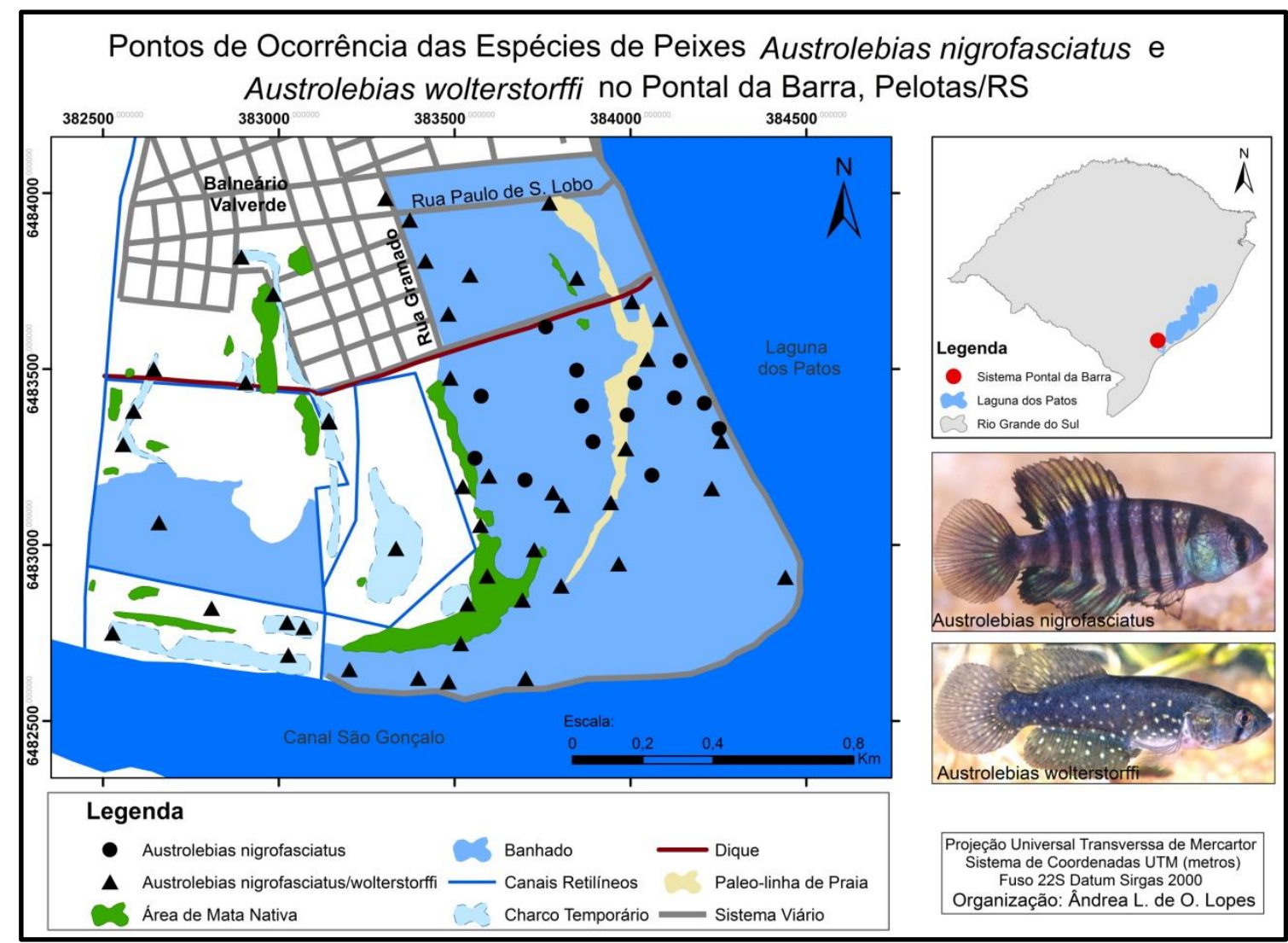

Fonte: Os autores

Obedecendo à sucessão dos ciclos, Austrolebias nigrofasciatus ocorre ao longo de todos os banhados e charcos do Pontal da Barra, conforme ilustrado na figura 1. Austrolebias 
wolterstorffi, embora menos abundante e não apresentando ciclos sucessivos de eclosão, também ocorre de forma generalizada na área. O dique de contenção seccionou as populações locais das duas espécies, ou seja, as mesmas estão sem possibilidade de contato e fluxo gênico através dessa barreira.

\section{3 - Conclusões}

A diversidade de biótopos aquáticos verificada no Pontal da Barra, aliada a grande dispersão e abundância da espécie Austrolebias nigrofasciatus, assegura a esta população sua viabilidade genética e produzem a maior plasticidade intra-específica (Figura 2) conhecida para esse táxon - fatores que determinam a importância da área para a preservação global da espécie (Reis et al., 2003). A livre circulação das águas, determinada pelas enchentes sazonais, responsáveis pelo transporte mecânico de póslarvas e adultos, foi interrompida pela construção do dique, que secciona as populações em pré e pós-dique. Esse impacto, a médio e longo prazo, pode diminuir a viabilidade genética (através do cruzamento consangüíneo) e a plasticidade intra-específica, através da fixação de um único morfo e supressão dos demais.

Figura 2 - Morfos de Austrolebias nigrofasciatus encontrados no Pontal da Barra

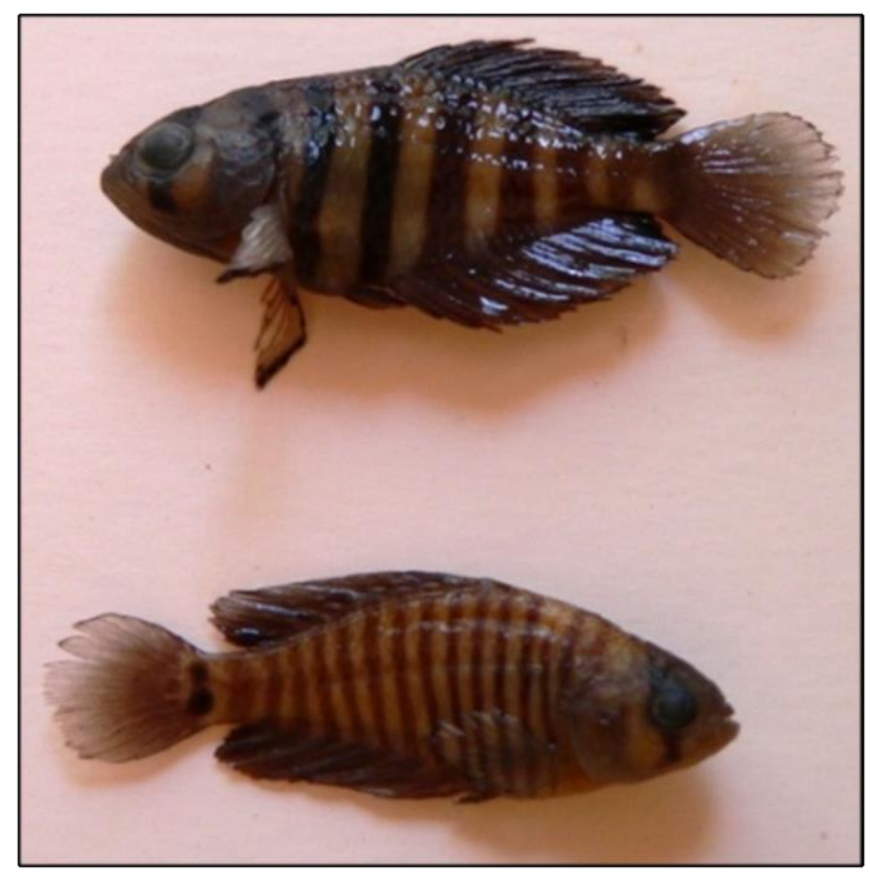

Fonte: acervo pessoal Cheffe, M.

Austrolebias wolterstorffi coabita em sintopia com A. nigrofasciatus muitas das mesmas áreas úmidas do Pontal da Barra. Essa espécie, que pertence ao clado das Megalebias 
(Costa, 2008), embora não partilhe da estratégia dos ciclos de eclosão, também se utiliza do período de cheias para melhor dispersão na área e troca de genes entre as suas subpopulações.

Ainda que a rua sobre a qual o dique foi construído já atuasse como barreira, verifica-se (conforme ilustrado na Figura 3) que em situação de cheia ocorria o contato (via lâmina d'água) entre as duas partes do banhado, sobre a rua, possibilitando o fluxo gênico natural das populações locais dos peixes mencionados. Ressalta-se que esse fluxo é fundamental para a conservação em longo prazo das espécies em questão, visto que populações pequenas e isoladas estão mais propensas à extinção.

Figura 3 - Vista aérea a partir da linha de praia (orientação leste-oeste) do banhado do Pontal da Barra, no momento do início da construção do dique, em novembro de 2015.

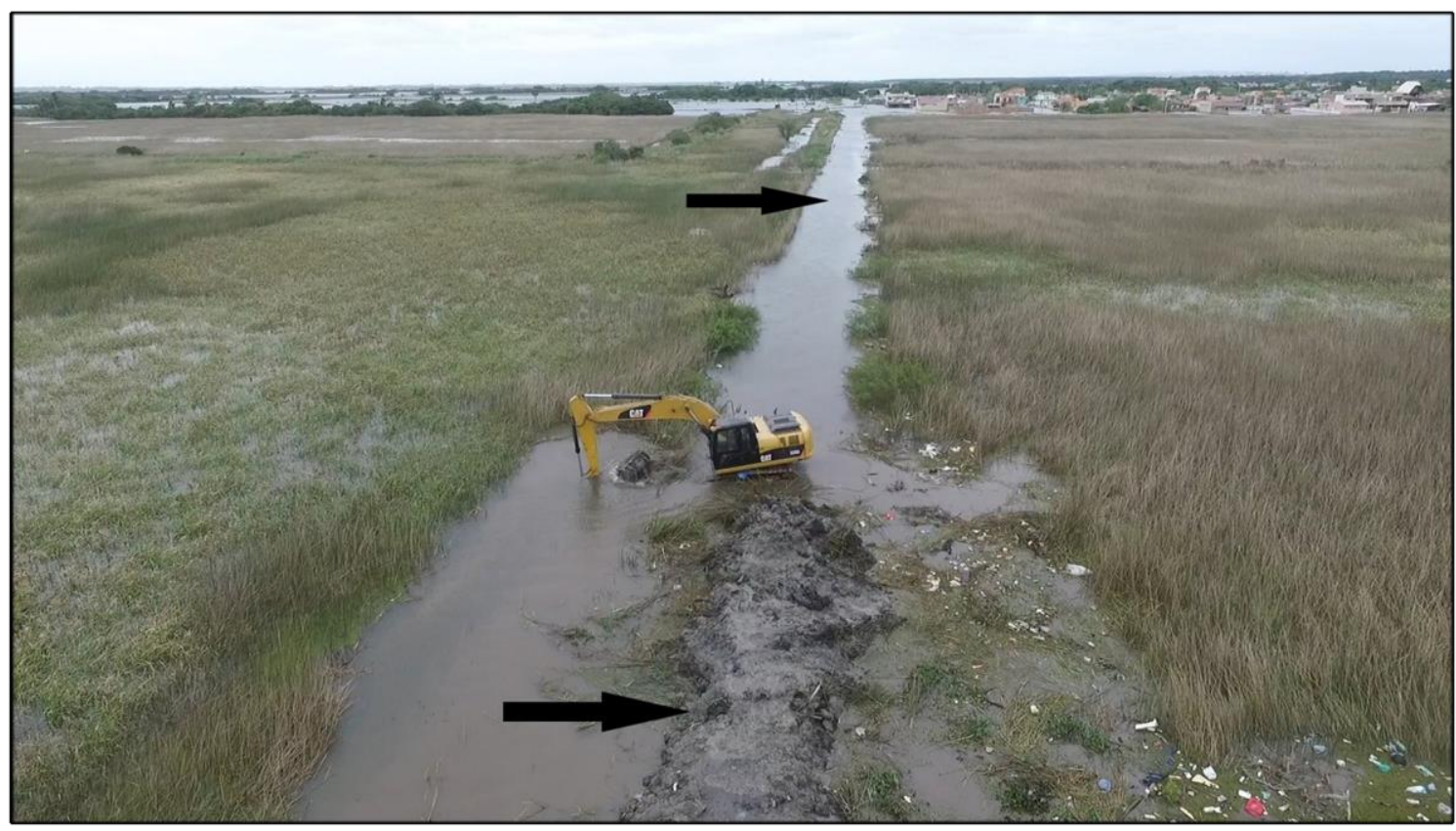

A seta acima destaca a lâmina d'água por sobre a via, permitindo o trânsito dos peixes anuais; a seta abaixo mostra o efeito de barreira do dique, com obstrução total de passagem por via aquática. Fonte: Topcam, 2015.

Cabe ressaltar que Austrolebias nigrofasciatus tem uma área de ocorrência muito restrita em nível global; além do Pontal da Barra, sua presença foi verificada apenas em duas pequenas áreas do município do Capão do Leão, onde é escassa. Nas áreas úmidas à margem direita do canal São Gonçalo, no município do Rio Grande, ao invés de Austrolebias nigrofasciatus verificasse a ocorrência de uma nova espécie do gênero Austrolebias que se encontra em fase de descrição formal (Costa \& Cheffe, em preparo). 
Portanto, Austrolebias nigrofasciatus é endêmica da margem esquerda do canal São Gonçalo e restrita aos municípios de Pelotas e Capão do Leão, como já havia sido definido por Costa (2006) na monografia de revisão do gênero Austrolebias, sendo que sua maior população conhecida - a única capaz de assegurar a conservação da espécie em longo prazo - está no Pontal da Barra.

Assegurando-se a conservação em longo prazo dessas espécies, também assegura-se a manutenção dos elos tróficos no sistema ecológico local, uma vez que ambas as espécies se alimentam de uma gama de invertebrados aquáticos e, ao mesmo tempo, servem de alimento para peixes maiores e aves aquáticas piscívoras.

Cabe destacar que Austrolebias nigrofasciatus e Austrolebias wolterstorffi foram oficialmente reconhecidas como espécies ameaçadas de extinção em nível nacional e estadual desde o início dos anos 2000, tendo sido mantidas nessa situação nas revisões recentemente publicadas (Brasil 2014, Rio Grande do Sul 2014). Conforme ilustrado na figura 3, a construção do dique decididamente irá causar uma perturbação na dinâmica natural das populações dessas espécies sensíveis, motivo pelo qual sugere-se aqui algumas medidas para evitar a continuidade dos impactos negativos sobre as mesmas: 1) eliminação do dique atual; 2) construção de outro dique junto à área urbana já consolidada, especificamente junto às ruas Gramado e Paulo de Sousa Lobo, preservando-se os trechos de banhado imediatamente limítrofes à essas vias públicas, visto que tais trechos são locais de ocorrência e reprodução dos dois peixes anuais; 3 ) ampliação da RPPN do Pontal da Barra, ou criação de outra reserva, de modo a garantir a conservação em longo prazo de toda a área habitada pelos peixes ameaçados.

\section{REFERÊNCIAS}

BRASIL. Portaria no 445, de 17 de dezembro de 2014. Ministério do Meio Ambiente. Diário Oficial da União, Brasília, 18 de dezembro de 2014, nº 245, p. 126-130.

COSTA, W. J. E M. The South American annual killifish genus Austrolebias (Teleostei: Cyprinodontiformes: Rivulidae): phylogenetic relationships, descriptive morphology and taxonomic revision. Zootaxa, Auckland, n. 1213, p. 1-162, maio, 2006.

COSTA, W. J. E. M. Catalog of Aplocheiloid killifishes of the World. Rio de Janeiro: UFRJ, Departamento de Zoologia, 2008. 120 p. 
LIMA, F. C. T. Austrolebias nigrofasciatus. In: Machado, A. B. M.; Drummond, G. M.; Paglia, A. P. (Eds.). Livro Vermelho da Fauna Brasileira Ameaçada de Extinção. Brasília: Ministério do Meio Ambiente, 2008. P. 119-120.

ODUM, E. P. Fundamentals of Ecology. Philadelphia: W. B. Saunders Company, 1959. $570 \mathrm{p}$.

REIS, R. E.; LUCENA, Z. M.; LUCENA, C. A. S.; MALABARBA, L. R. Peixes. In: FONTANA, C. S.; BENCKE, G. A.; REIS, R. E. (Orgs.). Livro Vermelho da Fauna Ameaçada de Extinção do Rio Grande do Sul. Porto Alegre: Edipucrs, 2003. 632 p.

RIO GRANDE DO SUL. Decreto Estadual n 51.79708, de 08 setembro de 2014. Declara as espécies da fauna silvestre ameaçadas de extinção no Rio Grande do Sul. Diário Oficial, Porto Alegre, 09 de setembro de 2014, p. 2-12.

SILVA, A. R. E. et al. Nota técnica referente à construção do dique de contenção no Pontal da Barra, Laranjal (Pelotas, RS). Revista Geographia Meridionalis, Pelotas, v. 01, nº 02, p.412-418, Jul/Dez. 2015. 